Galina V. Olenina, Dr. of Pedagogical Sciences, Professor Altai State Institute of Culture (Barnaul, Russia) ustlama@mail.ru

\title{
PEDAGOGICAL THEORY OF PROJECTIVITY OF INITIATIVE SOCIAL AND CULTURAL ACTIVITIES
}

\begin{abstract}
The paper starts a series of articles outline the author's views on term system of theory of projectivity of initiative social and cultural activities and disclose complicated system of subjects, functions, principles of projects activity and measures for promoting social and creative projects in youth voluntary work and youth government that the author numbers along the most important civil initiatives for the today's Russian young people.

On the author's opinion, theoretical and methodological basis for research in projecting process took shape by the beginning of the $21^{\text {st }}$ century as a result of synthesis of philosophical, social, cultural, naturalistic, technical and technological components. For now, the issue about structure, functions of projects initiative activity considered as a sort of social and cultural activities still has not answered with a lack of definition of actors, structure, functions of social and cultural activities as well as without carefully elaborated term "social and cultural activities". The article outlines the author's thoughts concerning the key senses of this scientific conceptual object from the points of view of social and cultural methodological approach in cultural studies, ideas of anthropogenesis from philosophical anthropology, and ideas of cultural micro dynamics.

Key words: initiative social and cultural activities, civil initiatives of student youth, pedagogical concept of projectivity of initiative social and cultural activity, voluntary work (volunteering activity), student government, student youth education efficiency.
\end{abstract}

УДК [378.1:008-057.87]:745/749-051

DOI: $10.32340 / 2414-9101-2020-4-50-55$

Л. В. Шокорова, кандидат искусствоведения, доцент Алтайский государственный институт культуры (Барнаул, Россия) larazmei@mail.ru

\section{О КОМПЕТЕНЦИЯХ ХУДОЖНИКА-ПРИКЛАДНИКА В УСЛОВИЯХ НОВОГО СОЦИАЛЬНОГО ЗАКАЗА}

\begin{abstract}
Аннотация. Представлен авторский взгляд на проблемы подготовки художников декоративноприкладного искусства в отечественной высшей школе, обусловленные современными социальнокультурными и экономическими условиями. Определены причины неготовности выпускников вузов к самостоятельной творческой работе. Выделены базовые знания и умения, составляющие основу профессиональной компетентности художников-прикладников. Показано, что расширенный спектр знаний в области изобразительной грамоты, технической эстетики, техники и технологии обработки различных декоративных материалов, а также развитое декоративное мышление и богатое воображение способствуют конструированию новых образов реальной действительности. Выявлены и обоснованы способы эффективного формирования профессиональной компетентности студентов, заключающиеся в целенаправленной активизации познавательной деятельности посредством рисования с натуры и копирования образцов народного искусства.

Ключевые слова: высшее образование, профессиональная подготовка, художник декоративноприкладного искусства, художник-прикладник, методика обучения, декоративно-прикладное искусство, компетентностный подход, художественный образ.
\end{abstract}

Профессиональная подготовка художников декоративно-прикладного искусства в системе высшего образования в настоящее время является одной из наиболее актуальных и сложных проблем 
педагогической науки. Акцентирование на прикладных искусствах обусловливается их огромным потенциалом в формировании духовно-нравственных качеств, мировоззрения и ценностных ориентаций у молодого поколения как базового фундамента национальной идентичности. Именно будущие художники-прикладники своими творческими произведениями способны противостоять унификации и ассимиляции культурных ценностей, нарастанию единообразия и стереотипности, создающих угрозу утраты национального достоинства, индивидуальности и самобытности. Известно, что вечными истинами во всей истории человечества, которые не подлежали сомнению, являлись нравственность, культура и красота. В. В. Корешков отмечает: «Только культурная среда, в которой организующую роль играет прикладное искусство, поможет каждому члену общества осознать важность уникальности своей социокультурной идентификации, на основе которой воспитывается уважение к своей истории, национальным традициям, культуре, формируется патриотизм» [1, с. 179].

Следует подчеркнуть, что методика обучения декоративно-прикладным видам творчества в отличие от изобразительных искусств стала активно исследоваться только в конце XX века. Более того, имея множество видов и типов, а также сопутствующих областей (рисунок, живопись, композиция и т. д.) прикладные искусства подверглись размежеванию на отдельные методики, не имеющие ничего общего между собой. Несомненно, каждый вид прикладного искусства - это конкретный декоративный материал, требующий знаний о его пластических, физических и пластических свойствах, специальных умений работы с ним. Но вместе с тем никакие практические навыки в обработке материала не позволят создать выразительное произведение, если художник не умеет придумать оригинальную художественную идею, сформировать образный композиционный замысел. Л. Г. Медведев конкретизирует, что «создание убедительного произведения зависит от степени сформированности замыслапредставления, являющегося основой художественного образа» [2, с. 9].

Опыт собственной педагогической практики свидетельствует, что студенты, получив за период обучения в разной степени базовые знания, по окончанию вуза практические не готовы к продуктивной самостоятельной профессиональной деятельности. Более того, они не всегда осознают, где и как им проявить себя как профессионала, хотя возможностей для официального трудоустройства сегодня предостаточно. Проходившие практику на различных предприятиях, выпускники вузов прекрасно понимают, что в ближайшие годы они будут материализовать только чужие замыслы, нарабатывая исполнительское мастерство. Разработкой авторских произведений за редким исключением молодые специалисты практически не занимаются, что связано со спецификой бизнеса, конкретным ассортиментом выпускаемой продукции, потребностями рынка и, конечно же, неумением выпускников быстро генерировать идеи произведений в соответствии с социальным заказом, грамотно проектировать и качественно их воплощать в материале.

Одурманенные свободой и личной значимостью, молодые люди, желая сразу стать богатыми и успешными, пытаются самостоятельно выйти на художественный рынок, достаточно насыщенный различными арт-площадками, на которых молодой художник казалось бы может реализовать себя. Однако жесткая конкуренция, неумение презентовать и продавать себя не позволяет быстро попасть в закулисье мира искусства. В итоге обостряется невостребованность и происходит переквалификация в иную, часто не связанную с искусством, сферу деятельности. Не случайно в союзах художников многих регионов академистов в десятки раз больше, чем прикладников.

Таким образом, в новых социально-экономических условиях требуется кардинальное «переформатирование» процесса подготовки художников-прикладников, сущностная и конкретная разработка новых методик обучения, способных перезагрузить сознание и мышление, как самих студентов, так и преподавательского состава. Ибо есть такие фундаментальные знания и умения, которые обучающиеся могут получить только в стенах вуза и при правильной установке реализовать и усовершенствовать их вне его. А. В. Хуторской подчеркивает: «Весь полный набор необходимых компетенций должен быть фундаментально подготовлен в высшем учебном заведении. При необходимости приобретенные компетенции успешно видоизменяются уже на конкретном производстве, если этого требуют производственные изменения» [3, с. 11].

В первую очередь, представляется необходимым выявить какими фундаментальными знаниями и навыками должен овладеть выпускник вуза - будущий художник-прикладник для успешной самореализации в профессиональной сфере, и на этой основе определить пути формирования ведущих 
компетенций. В. С. Сенашенко конкретизирует: «При использовании компетентностного подхода важно выбрать такие формы и методы обучения, а также их сочетания, которые позволят целенаправленно, результативно и эффективно формировать запланированные компетенции выпускников» $[4$, c. 22].

Итак, для того, чтобы вписаться в современный художественный рынок (мы считаем это крайне важным - в ином случае прикладное творчество будет выступать лишь в форме хобби) начинающие художники, несомненно, должны в совершенстве владеть профессиональным мастерством. Но вместе с тем им необходимо обладать и социальной активностью, как способностью анализировать существующие духовно-эстетические и утилитарные потребности общества и прогнозировать будущее развитие социально-культурной и предметно-пространственной среды. Как раз отсутствием предрасположенности к прагматическим шагам и славятся многие художники изобразительного и прикладного искусства. Начиная с ренессансной Европы и до начала прошлого века эту функцию выполняли меценаты, положив начало истории коллекционирования. Сегодня при явной нехватке галеристов и аукционистов молодым дарованиям нужно самим научиться продавать свое искусство. Известно, что произведения искусства приобретаются, если вызывают у зрителя яркий эмоциональный отклик, пробуждают эстетическое наслаждение и ощущение красоты. И создать такое произведение может лишь творец, глубоко понимающий одновременно художественною содержательность создаваемого произведения и конъюнктуру требований арт-рынка.

Единство содержания и формы в декоративно-прикладном искусстве неразрывно связано с целесообразностью, которая эстетически оценивается человеком. Форма, обусловливая назначение вещи, непосредственно зависит от выбранного художником и содержательно преобразованного материала. Художественное содержание конкретной вещи проявляется посредством эмоционального претворения мысли, темы, идеи, положенной в основу произведения. Выражающее чувство, переживание или настроение, вложенное художником в создаваемую им вещь, форма становиться не просто красивой, но и выразительной, оказывающей эмоциональное воздействие на зрителя. «Для искусства преобразовательного нужно знать о мире гораздо больше, чем знают академические художники так, как легче изобразить существующий горшок, чем его создать» [5, с. 21].

Из этого следует, что от художника-прикладника требуются глубокие знания теории искусства и высокая степень владения мастерством, позволяющие в совокупности так преобразовать декоративный материал, выявить его фактуру, найти такие пропорции и цветовые отношения, которые бы ясно выразили его душевное состояние и «заразили» им зрителя. Для создания декоративного произведения требуется расширенный спектр знаний в области изобразительной грамоты, технической эстетики, техники и технологии обработки различных декоративных материалов, а также развитое декоративное мышление и богатое воображение, способствующие конструированию новых оригинальных образов реальной действительности.

Именно эти фундаментальные знания и должны приобретаться в вузе посредством широкого блока гуманитарных дисциплин, таких как философия, культурология, история, социология, эстетика, экономика и основополагающих художественных учебных дисциплин. «Дисциплины гуманитарного цикла в вузовском обучении расширяют возможности для развития когнитивного аппарата будущих художников и формирования у них социокультурных компетенций, необходимых для создания высокохудожественных произведений прикладного искусства» [6, с. 34].

Кроме того, гуманитарная составляющая служит формированию мировоззренческих позиций и определению смысловых жизненных приоритетов, развитию духовно-нравственных основ личности, способной к эстетическому преобразованию мира. Собственно ценность высшего образования, отличающая его от СПО, заключается в формировании «культуры универсального миропонимания, развитии личности, открытой к усвоению новых знаний, умеющей адаптироваться к новым информационным, технологическим и мировоззренческим парадигмам, обладающей потребностью в самообразовании» [7, с. 88$]$.

Современное высшее образование преимущественно готовит художников, способных копировать, варьировать и отчасти проектировать авторские произведения в конкретном виде декоративного материала. Несомненно, за период обучения студенты достигают определенного уровня владения профессиональным мастерством, если рассматривать его с точки зрения практических навыков обра- 
ботки материала. Однако собственная деятельность автора статьи в качестве председателя и члена жюри различных профессиональных конкурсов свидетельствует, что выпускники вузов крайне редко принимают участие в выставочной деятельности, экспонируют свои произведения на арт-площадках, фестивалях ремесел и т.д. Поэтому крайне важно в процессе обучения в вузе сформировать у студентов высокие эстетические потребности, базирующиеся на понимании сущности гармонии в искусстве, снабдить их теоретическими и практическими знаниями о различных культурах, теории творчества, изобразительной грамоты и техники и технологии обработки декоративных материалов. «Учебный процесс в вузе должен обеспечивать развитие субъектности и профессионализацию будущего специалиста, воспитательный процесс - формирование личностных свойств и качеств, а образовательный процесс - становление индивидуальности, как целостной неповторимости» [8, с. 385].

Таким образом, формирование компетентностной личности художника-прикладника, способного к дальнейшему саморазвитию и самосовершенствованию по нашему убеждению заключается в приобретении способности преобразовывать окружающий мир посредством создания высокохудожественных декоративных произведений, обладающих эстетическими качествами и учитывающих потребности современного социума.

Соответственно, ведущей компетенцией художника-прикладника выступает умение формировать образно-выразительный замысел будущего произведения на основе собственного стремления в создании определенного произведения как желания сообщить людям что-то новое и важное, инициировать у них эстетическое переживание, а также анализа художественного рынка и окружающей среды. «Поиск идеи начинается тогда, когда человек осознает и представляет себе будущее, т.е. оптимальные условия, которые необходимы как для реализации собственных потенциальных возможностей, так и удовлетворения потребностей общества в целом» [9, с. 29].

Очевидно, что материализация сформированного замысла немыслима без высокой художественной подготовки как умения изобразительными средствами передать художественное и эстетическиобразное решение будущего изделия и отразить предполагаемые способы его выполнения. А. С. Хворостов писал, что без эскизных поисков и разработок «мастер подобен слепому, бредущему без поводыря. Быть может, он и дойдет до завершения изделия, но с большими потерями как в его образно-выразительном решении, так в количестве затраченного времени» [10, с. 336]. При этом для материального воплощения художественных идей требуются глубокие знания физико-химических свойств материала, совершенное владение технологиями его обработки, умение работать специальными инструментами и приспособлениями. Сформированный замысел, заполнивший все мысли и чувства художника, направляет его к активному освоению материала, в котором задумано произведение, отработке определенных технических действий и экспериментированию с ним.

Следовательно, важнейшее значение в образовательном процессе приобретает формирование способности к поиску новых и оригинальных идей. В этой связи методические воздействия следует направить на активизацию познавательных процессов студентов, развитие их наблюдательности и внимательности при восприятии окружающего природного мира и работ других художников. Здесь в качестве активизации познавательной деятельности наиболее эффективно выступает рисование с натуры и копирование образцов народного искусства. Натурные зарисовки помогают детально изучить пластику, конструкцию, объем и другие типические характеристики воспринимаемых объектов природного мира, которые зачастую становятся источником вдохновения для прикладников. Накопленный в сознании багаж образов позволяет в момент вынашивания идеи легко генерировать новые оригинальные формы. Педагогическая установка на выявление декоративных свойств предмета развивает способность видеть особенное и индивидуальное в явлениях и событиях, отсекать ненужную информацию, выявлять самое главное для передачи художественного образа посредством условнознаковой формы, что составляет важную часть профессиональной компетентности художника.

Копирование произведений народного искусства способствует глубокому погружению в мир традиционной культуры, пониманию символов и художественных значений, в контексте которых происходит овладение языком прикладного искусств, ценными техниками и приемами обработки декоративного материала. Личностное вживание и вчувствование (эмпатия) в процесс копирования оригиналов позволяет превращать чужие художественные смыслы в собственные результаты творчества, обогащающие рост и развитие художника. Анализ и интерпретация художественно- 
стилистических особенностей копируемого объекта углубляет освоение эстетических принципов конкретного этноса, как «способности человеческого сознания отражать сложность и многомерность мира, выраженную в теоретическом и практическом опыте» [11, с. 26].

Вместе с тем, изучение творчества местных мастеров и музейных экспозиций способствует погружению в региональную художественную культуру, активизирует желание проявить себя в профессиональной среде и осознать свою национальную идентичность и индивидуальную неповторимость. Эмоционально-личностное отношение к процессу деятельности, направляемое смыслом работы и эстетическим чувством художника формирует рефлексию в отношении себя и потребностей общества, обеспечивая на новом, более высоком уровне способность к мотивированному саморазвитию. «Воспитание активной жизненной и профессиональной позиции личности включает развитие внутренней профессиональной мотивации, любви к своей профессии, формирование знаний, умений и навыков, необходимых для высококвалифицированного профессионала» [12, с. 90].

Таким образом, совершенствование профессиональной подготовки художников-прикладников в современной системе высшего образования заключается в углублении формирования следующих компетенций:

1) способность к формированию оригинальной идеи произведения, соответствующего духовноэстетическим и практическим потребностям современного социума;

2) способность к личностному стремлению в создании выразительного эмоционального произведения как желания в определенном материале эстетически выразить свои чувства, настроение, мысли;

3) способность изобразительными средствами передать исчерпывающую информацию о художественном и эстетически-образном решении будущего изделия и предполагаемых способах его выполнения;

4) способность на высоком уровне технически материализовать художественную идею посредством работы специальными инструментами и приспособлениями по обработке декоративного материала.

Обозначенный комплекс компетенций формируется на основе широкого блока гуманитарных дисциплин, включающих изучения историко-культурных и этнохудожественных особенностей своего региона, а также общепрофессиональных и профессиональных учебных предметов, позволяющих приобрести знания изобразительной грамоты и технических умений в обработке материала. К наиболее эффективным способам формирования идейного замысла относится рисование с натуры региональных природных образов и изучение творчества местных мастеров народного и декоративноприкладного искусства. Копирование, варьирование и интерпретация произведений прикладного искусства предполагает не формальное «цитирование» и прямое заимствование, а возможность выработать новые выразительные средства и найти иные сюжетные линии. На основе приобретенного опыта обогащается собственное развитие художника, проявляющееся в переосмыслении традиционной практики создания декоративно-прикладных вещей.

Итак, в сложных социально-экономических и культурных условиях совершенствование связей «человек - эстетически развивающая среда» приобретает колоссальные проблемы, вызванные ассимиляцией культурных ценностей под мощным влиянием массовой культуры. Поэтому в фокусе научных исследований выступают проблемы поиска новых форм ознакомления молодого поколения с мировым и отечественным национально-культурным наследием, в котором декоративноприкладное искусство играет ведущую роль. Выступая интегрированным качеством личности, профессиональная компетентность объединяет в себе личностные качества художника, включающие развитую эмоциональную и смысловую сферу, способствующие определению ценностных ориентиров в поиске идеи будущего произведения. А также теоретические и практические знания, умения и навыки, позволяющие воплотить свой замысел в материале.

Сформированная профессиональная компетентность выступает как характеристика и степень творческой работы художника и как мера гармонии в формообразовании эмоциональновыразительного предмета с четкими пропорциями и очертанием, гармоничными цветовыми отношениями, ясной фактурой, в совокупности выражающая определенное душевное состояние и настроение, заражающее зрителя, формирующее его мировоззрение и ценностные ориентации. Совершен- 
ствование процесса профессиональной подготовки художников-прикладников способно значительно увеличить возможности формирования национальной идентичности посредством создания высокохудожественных декоративных произведений, служащих преобразованию жизни и себя как личности.

\title{
Список литературы
}

1. Корешков, В. В. Роль образовательной области «Искусство» в воспитании молодёжи // Современные тенденции развития культуры, искусства и образования : [кол. моногр.]. - Москва : Перо, 2017. - С. $178-186$.

2. Медведев, Л. Г. О проблемах художественно-педагогического образования // Вестник Московского государственного областного университета. Сер. : Методика обучения изобразительному и декоративному искусству. - 2007. - № 2. - С. 8-10.

3. Хуторской, А. В. Структура и содержание компетентностного учебника для вуза // Высшее образование сегодня. - 2020. - № 1. - С. 8-13.

4. Сенашенко, В. С. О компетентностном подходе в высшем образовании // Высшее образование в России. -2009 . - № 4. - С. 18-24.

5. Shokorova, L. V. Revisiting the problem of teaching students to decorative and applied arts / L. V. Shokorova, L. G. Medvedev // Espacios. - 2018. - No. 39. - Pp. 19-25.

6. Теплицкая, А. А. Роль гуманитарных дисциплин в вузе художественной направленности (на примере профессионального образования в области традиционного прикладного искусства) // Высшее образование сегодня. -2019 . - № 3. - С. 31-35.

7. Илькевич, Б. В. Философия искусства и мотивирующее обучение будущих художников / Б. В. Илькевич, Л. Т. Усманова // Человек и образование. - 2019. - № 2. - С. 87-90.

8. Шачкова, Э. В. Творческий потенциал будущих художников декоративно-прикладного искусства в условиях самостоятельной работы // Учёные записки Орловского государственного университета. - 2017. № 2. - С. 384-387.

9. Никифорова, О. И. Исследования по психологии художественного творчества. - Москва : Изд-во Московского ун-та, 1972. 155 с.

10. Хворостов, А С. Специфика рисунка в декоративно-прикладном искусстве // Учёные записки Орловского государственного университета. - 2009. - № 1. - С. 336-339.

11. Барахсанова, Е. А. Трансдисциплинарный подход как стратегическая основа развития этнокультурного образования в Якутии / Е. А. Барахсанова, М. С. Прокопьев // Азимут научных исследований: педагогика и психология. - 2019. - Т. 8, № 4. - С. 25-28.

12. Севрюкова, Н. В. Художественное восприятие как часть профессиональной компетенции специалиста декоративно-прикладного искусства // Педагогика искусства. - 2015. - №4. - С. 89-96.

Larisa V. Shokorova, Ph. D. in Art History, Associate Professor Altai State Institute of Culture (Barnaul, Russia)

larazmei@mail.ru

\section{ON SKILLS SET OF AN APPLICATION ARTIST IN ENVIRONMENT OF A NEW SOCIAL DEMAND}

\begin{abstract}
The paper outlines the author's view on problems in teaching of application artists in the modern Russian higher education caused by today's social, cultural and economic conditions and challenges. Reasons for unpreparedness of graduates of institutions of higher education to independent creative labor are called. A circle of knowledge and skills that are fundamental for a professional application artist-to-be are named in the article. It is shown that widened knowledge of visual skillfulness, technical aesthetics, methods and technologies of materials handling as well as developed artistic thinking and imagination help to create new images of the reality. Also, the paper reveals ways of building students' professionally significant skills that are consists in wake-up task-oriented cognitive activities through life drawing, copying examples of folk art.
\end{abstract}

Keywords: higher education, professional training, a craftsman in applied art, an application artist teaching methods, arts and crafts (applied art), competency-based approach, an artistic image. 